\title{
INOVAÇÃO SOCIAL E ESTRATÉGIAS PARA A BASE DA PIRÂMIDE: MERCADO POTENCIAL PARA EMPREENDEDORES E PEQUENOS NEGÓCIOS
}

\author{
Rhubens Ewald Moura Ribeiro - PPGADM/UFPR ${ }^{1}$ \\ Andréa Paula Segatto - PPGADM/UFPR ${ }^{2}$ \\ Taiane Ritta Coelho - PPGADM/UFPR ${ }^{3}$
}

Resumo: O mundo pede por novos modelos de negócios que colaborem com o desenvolvimento local das comunidades. Existe um mercado potencial localizado na base da pirâmide, a qual é composta pelos menos favorecidos economicamente. A concepção de modelos de negócios para servir aos mais pobres pode ser desenvolvida em conjunto com estratégias que trabalhem a inovação de uma maneira social. Nesta linha, o presente trabalho analisa teoricamente a inter-relação entre inovação social e estratégias de negócios para a base da pirâmide, identificando as oportunidades emergentes para empreendedores e pequenas empresas. Constata-se uma inter-relação entre os temas que provocam externalidades positivas para a sociedade e potencial de mercado para empreendedores e pequenas empresas, que ao olharem para a base da pirâmide podem identificar negócios sociais, contribuir para a transformação da sociedade de maneira positiva e encontrar ao mesmo tempo novas oportunidades de negócio.

Palavras-chave: Base da Pirâmide; Inovação Social; Empreendedorismo; Pequenas Empresas.

\section{SOCIAL INNOVATION AND STRATEGIES FOR THE BASE OF THE PYRAMID: POTENTIAL MARKET FOR ENTREPRENEURS AND SMALL BUSINESS}

Abstract: The world calls for new business models to collaborate with the local development of the communities. There is a huge potential market located at the base of the economic pyramid, which is composed of the economically disadvantaged. The design of business models to serve the poorest can be developed jointly with innovation strategies that work in a social way. In this line, this paper aims to analyze theoretical the relation between social innovation and strategies for bottom of the pyramid, identified the opportunities for entrepreneurs and small companies. The results showed an interrelationship between these themes which cause positive externalities for society and market potential for entrepreneurs and small businesses that when look for the bottom of the pyramid can identify social businesses, contribute for the transformation of society in a positive way and find new business opportunities.

Keywords: Base of the Pyramid; Social Innovation; Entrepreneurship; Small Companies.

\footnotetext{
${ }^{1}$ E.mail: rhubens7@yahoo.com.br

2 E.mail: aps@ufpr.br - Endereço: Rua Prefeito Lothário Meissner 632 - 2 andar - Jardim Botânico - CEP: 80.210-170 - Curitiba - PR.

${ }^{3}$ E.mail: taianercoelho@gmail.com
}

RIBEIRO, R. E. M; SEGATTO, A. P; COELHO, T. R. Inovação social e estratégia para a base da pirâmide: mercado potencial para empreendedores e pequenos negócios. Revista de Empreendedorismo e Gestão de Pequenas Empresas, v. 2, n.2, p.55-72, 2013. 


\section{Introdução}

Em acordo com estimativas do Banco Mundial, quatro bilhões de toda a população mundial vive com pouco mais de US\$ 2 dólares por dia, tendo condições apenas de satisfazer as suas necessidades mais fundamentais (GORDON; DAKSHINAMOORTHY; WANG, 2006). No entanto, Prahalad (2006) sugere que estas pessoas (os de "baixo" ou da "base" de uma distribuição de renda demográfica na forma de uma pirâmide) passem a ser vistas não mais como vítimas a serem assistidas, mas sim como potenciais consumidores sensíveis de valor.

É importante que o público corporativo compreenda que atuar na base da pirâmide exige pesquisa e desenvolvimento inovador devido às peculiaridades desse público. $\mathrm{Na}$ base da pirâmide, a criação, desenvolvimento e concepção de novos produtos que pretendem obter sucesso, demanda um entendimento mais completo das circunstâncias locais, de tal forma que as características que são críticas, bem como as funcionalidades, podem ser incorporadas ao projeto ou design do produto (HAMMOND; PRAHALAD, 2004).

Nesse cenário, a economia direcionada ao mercado vem impulsionando as organizações a estabelecerem um novo quadro que tolere ajustar as estratégias de negócios às necessidades da tecnologia e da competição demandadas pelo mercado. Desafios diários conduzem a reflexões e questionamentos na busca de identificar inovações que transformam comportamentos, posicionamentos e trajetórias (FARFUS et al., 2007).

O enfoque em inovação pode proporcionar a prosperidade no futuro. A criação de valor para os stakeholders é dependente da habilidade que a empresa possui para a destruição criativa de suas capacidades em prol das inovações de amanhã. Com isso, o futuro será guiado pelas empresas que forem capazes de desenvolver tecnologias que se enderecem às necessidades da sociedade (HART; MILSTEIN, 2003).

Linhares (2013) afirma que a inovação pode ser compreendida como uma ação ou prática que surge do intuito de quebrar um paradigma em vigor na busca de satisfazer novas necessidades ou demandas. Nesse contexto, a sociedade parece 
iniciar um novo movimento, saindo de um estado de acomodação ante as mudanças que intensificaram ou trouxeram à tona muitos problemas, tais como: o crescimento da desigualdade social, do desemprego e da exclusão social. Com isso, a lógica do mercado sustentável começa a ser priorizada em detrimento do mercado competitivo e isolado, abrindo espaço para ideias empreendedoras.

Alguns autores identificam o empreendedorismo como um mecanismo para reduzir a pobreza (HART, 2005; MATTEN; CRANE, 2005; PEREDO; MCLEAN, 2006) particularmente na base da pirâmide, onde grupos socioeconômicos menos capitalizados financeiramente sofrem com a exclusão social e a negação da igualdade de acesso às oportunidades (BEHRMAN; GAVIRIA; SZEKELY, 2003). Prahalad (2006) sugere que há muitos empreendedores resilientes e criativos na base da pirâmide.

Nessa linha, o presente artigo discute a importância de se pesquisar inovação social e estratégias de negócios para a base da pirâmide, buscando compreender como esses assuntos se inter-relacionam, identificando oportunidades significativas para empreendedores e pequenas empresas. Em outras palavras, esta pesquisa pretende contribuir para o desenvolvimento do campo de estudos sobre empreendedorismo, identificando a existência de um mercado a ser ocupado por novos posicionamentos empresariais, os quais poderiam ser criados por empreendedores e pequenas empresas.

$\mathrm{O}$ artigo apresentou neste tópico uma introdução que contextualiza os assuntos que serão discutidos. Em seguida, é feita uma breve apresentação do termo inovação. Na sequência, são apresentados conceitos e discussões sobre inovação social e base da pirâmide. No quinto tópico discute-se o interrelacionamento dos dois temas iniciais e como podem representar oportunidades para os empreendedores e pequenas empresas. Por fim, são apresentadas as considerações finais e as referências utilizadas. 


\section{Inovação}

De acordo com o Manual de Oslo, inovação é a inserção de um produto (bem ou serviço) novo ou expressivamente aprimorado nas práticas de negócios, na organização do local de trabalho ou nas relações externas. Pode ser ainda um processo, um novo método de marketing ou um novo método organizacional nas práticas de negócios. Em síntese, existe inovação de quatro tipos: a de produto, de processo, de marketing e organizacional (OECD, 1997).

Sarkar (2008) sugere que a inovação seria diferenciada conforme dois aspectos: no aspecto macro, no qual estaria relacionada às novidades para todo o mundo, a indústria e o mercado; e no aspecto micro, onde seria vista como uma espécie de novidade para a própria empresa e/ou para o consumidor. A inovação seria uma maneira das empresas criarem valor e com isso, distinguir os produtos e serviços oferecidos por elas, potencializando seus resultados (SARKAR, 2008).

Um conceito relacionado é o de inovações disruptivas (produtos inicialmente inferiores que proporcionem uma proposta de valor diferente sobre produtos incumbentes). Isto é, aquelas inovações que rompem e redefinem a trajetória da organização, dando origem a novos mercados e modelos de negócio (CHRISTENSEN, 1997). A inovação disruptiva altera as bases de competição existentes por meio da ruptura de um velho modelo de negócio, causando impacto significativo no mercado e na atividade econômica das empresas (CÂNDIDO, 2012).

$\mathrm{O}$ conceito de inovação diz respeito às mudanças que estão associadas à incerteza sobre os resultados das atividades inovadoras, envolvendo investimentos que podem render retornos potenciais no futuro. É O substrato dos transbordamentos de conhecimento e requer a utilização de conhecimento novo, ou ainda, um novo uso ou combinação para o conhecimento existente. Sendo assim, a inovação almeja aprimorar o desempenho de uma empresa com ganho de uma vantagem competitiva por meio da alteração da curva de demanda de seus produtos e dos custos, ou pelo refinamento da capacidade de inovação da empresa (FARFUS et al., 2007). 
A inovação está intimamente ligada aos negócios e, portanto, ao desenvolvimento econômico. De acordo com Schumpeter (1985, 2002), para a economia sair de um estado de equilíbrio e entrar em um processo de expansão, são necessárias as inovações. Nesse processo inovativo, a função empreendedora tem papel crucial. Um dos pontos chave de sua teoria é a noção de que a inovação tem caráter social e não personalizado.

Para compreender a situação atual de um ambiente empresarial é importante analisar as condições sociais, legais, tecnológicas e demais condições sobre as quais ele foi construído no seu percurso histórico. Schumpeter apontava a importância da função empresarial e empreendedora no processo de evolução dos mercados e da sociedade, afirmando que estava intrinsecamente ligada à ação de inovação tecnológica e à inovação pura e simples. Schumpeter ainda propõe a relação entre ganhos excedentes e inovação ou pioneirismo. Contudo, a combinação ou adaptação de meios ou ferramentas existentes, também possibilita a criação do novo.

O desenvolvimento econômico conduzido pela inovação é um processo dinâmico no qual as novas tecnologias substituem as antigas. Sendo assim, a inovação é um elemento relevante na busca pela melhoria e evolução dos mercados e sociedade. Por sua vez, o desenvolvimento de inovações é um processo dinâmico e cumulativo, dependente do caminho seguido (trajetória tecnológica). Ou seja, as possibilidades futuras estão fortemente conectadas ao que se realizou no passado (DOSI, 1982; FARFUS et al., 2007).

Um desdobramento do conceito de inovação é a inovação social como, por exemplo, no caso do Grameen Bank em Bangladesh (HART, 2005), um banco que oferece microcrédito para os menos favorecidos economicamente, tornando-se uma fonte de criatividade e inovação.

\section{Inovação Social}

A saturação dos mercados dos países desenvolvidos, o crescimento do fosso entre ricos e pobres, o aumento dos níveis de degradação ambiental e a 
preocupação de que o mundo desenvolvido possa estar perdendo o controle sobre sua densidade populacional, vêm se combinando e gerando percalços à economia global (HART; MILSTEIN, 2003). Tais inter-relações mostram as complexidades que são partes do meio ambiente natural e dos sistemas de aprendizagem humana, demandando uma constante abordagem holística (UNESCO, 2005).

Farfus et al. (2007) apresentam um conceito de inovação social proposto pela FINEP (Financiadora de Estudos e Projetos), onde se discute o conceito de inovação para o desenvolvimento social como sendo aquele que permite a concepção de tecnologias, processos e metodologias originais que possam vir a se tornar propostas de novos modelos e paradigmas para o confrontamento de problemas sociais, combate à pobreza e promoção da cidadania. A inovação social, nesse contexto, é aprendida como a utilização de tecnologias que permitam fomentar a inclusão social, geração de trabalho, renda e melhoras nas condições de vida.

Pode-se dizer que uma inovação social acontece quando ocorrem mudanças nos processos e relações sociais, alterando as estruturas de poder preexistentes. Desta forma, o processo de inovação tem o efeito de reconstruir os sistemas de relações sociais e a estrutura de regras (FLEURY, 2001). O conceito de inovação social é usado para fazer alusão ao conhecimento (intangível ou incorporado a pessoas ou equipamentos - tácito ou codificado) que tem por finalidade o aumento da efetividade dos processos, serviços e produtos arrolados à satisfação das necessidades sociais (DAGNINO, 2009; DAGNINO; BRANDÃO; NOVAES, 2004; DAGNINO; GOMES, 2000).

Quando se trata de inovação social, é necessário salientar a importância do grau de novidade e da contribuição para a construção e disseminação do conhecimento voltado para o mercado, com base na aprendizagem organizacional. Deve-se incluir, ao lado desses ingredientes, o compromisso solidário com a transformação, o reconhecimento e a valorização do conhecimento do outro, o que permite a sustentabilidade do desenvolvimento, a busca da multiculturalidade no processo e as metodologias para a emancipação de todos os indivíduos (FARFUS et al., 2007). 
A inovação social pode ser entendida como a busca, descoberta, experimentação, desenvolvimento, imitação e adoção de "arranjos sociais alternativos" para produzir algo (FARFUS et al., 2007). Sendo assim, as inovações sociais são concebidas como eventos onde soluções inéditas são postas em prática, objetivando a resolução de situações que envolvam precariedade social (BRUNSTEIN; RODRIGUES; KIRSCHBAUM, 2008).

Grande parte das empresas pressupõe, de maneira equivocada, que o mercado da base da pirâmide não possui oportunidades de valor, sem ao menos tentar entender as possibilidades de atender aos mercados a que está acostumada a ignorar. Tal compreensão pode se tornar um agente potencializador do desenvolvimento de tecnologias inovadoras, produtos e serviços que atendam as necessidades daqueles em condições financeiras desfavorecidas, direcionando o desenvolvimento em múltiplos níveis dentro da economia (HART; MILSTEIN, 2003).

\section{Base da Pirâmide}

Uma área chave para a pesquisa sobre a base da pirâmide é investigar quais capacidades são necessárias para as companhias identificarem, desenvolverem e aproveitarem as oportunidades nesta base. As empresas podem cocriar negócios em conjunto com comunidades da base da pirâmide e não simplesmente venderem produtos de baixo custo estendendo seus sistemas de distribuição (HART, 1995; HART; DOWELL, 2010).

A base da pirâmide é composta pelos quatro bilhões de pessoas que ganham menos de $\$ 1.500$ dólares por ano para viverem. Isso mostra que a maior parte da população mundial é composta por pobres. Surgem muitas oportunidades de negócios para as firmas que resolverem atender e trabalhar junto a este mercado. As companhias com persistência e meios para competir pela base da pirâmide obterão como recompensa o aumento dos lucros e grande contribuição para a humanidade (PRAHALAD; HART, 2002).

De acordo com Campanholo, Fontes e Alves (2010, p. 6-7), a oportunidade surge quando as empresas "deixam de ver as pessoas que compõem a base da 
pirâmide como vítimas ou um fardo e começam a vê-las como empreendedores potenciais e consumidores conscientes". Essa situação emerge da essência das organizações, pois são criadas para atender necessidades da sociedade, ou seja, dos consumidores (RIBEIRO, 2013).

Entretanto, os problemas associados com a base da pirâmide (tais como a falta de instituições formais, a infraestrutura inadequada e o baixo nível de estudo) exigem das companhias um maior esforço para desenvolver novas capacidades, caso elas queiram desenvolver com sucesso modelos de negócios para servir a este mercado. Mesmo a iniciativa das corporações sendo importantes, tais estratégias incrementais não são suficientes. É relevante que companhias e escolas de negócios mudem e comecem a desenvolver estratégias que resolvam problemas sociais e ambientais, mais do que simplesmente reduzir os impactos negativos associados com as operações correntes delas (HART, 1995; HART, 2005; HART; DOWELL, 2010).

Hart e Dowell (2010) afirmam que, para desenvolver a capacidade estratégica para se trabalhar com a base da pirâmide, a força motora da sociedade é o atendimento das necessidades do público pertencente a este mercado, tendo como recurso chave a inovação, buscando-se uma vantagem competitiva para crescimento em longo prazo. Para isso, deve-se buscar responder a perguntas como: quais são as capacidades que as empresas necessitam para ter sucesso com estratégias na base da pirâmide? E como elas podem se legitimar na base da pirâmide?

Neste discurso, Hart e Christensen (2002) argumentam que os mercados da base da pirâmide proporcionam um ambiente de aprendizagem ideal para 0 desenvolvimento de inovações disruptivas, que pode ser um caminho na medida em que ajuda organizações na combinação de crescimento corporativo com responsabilidade social. Pequenas empresas e empreendedores iniciantes têm grande capacidade de atender a este público menos desprovido economicamente pelo fato de estarem localizadas mais próximas a este mercado potencial, bem como por possuírem grande flexibilidade para adaptarem-se às exigências e necessidades da base da pirâmide. 
É o tempo das organizações olharem para as estratégias de globalização através de uma nova lente de capitalismo inclusivo. Mas, fazer negócios com os quatro bilhões de pessoas que estão na base da pirâmide requer inovações e tecnologias em modelos de negócios (PRAHALAD; HART, 2002).

Para Ferro (2006), o mercado potencial existente na base da pirâmide apresenta oportunidades inéditas para a concepção e realização de negócios com o público que a compõe. Esse mercado pode ser oportunamente explorado por empreendedores e pequenas empresas em virtude de sua proximidade e inserção nesse mercado.

\section{Inovação Social, Base da Pirâmide e Oportunidades para Empreendedores e Pequenas Empresas}

Os mecanismos de mercado têm se mostrado sustentavelmente insuficientes, pois estimulam o consumo predatório e inconsequente. Os principais prejudicados no processo, isto é, a natureza e as próximas gerações, são interlocutores silenciosos. A visão sistêmica e de longo prazo se impõe, implicando mecanismos de decisão e de gestão que transpassam o interesse microeconômico imediato. A prosperidade artificial e o consumo predatório que a concentração de renda e de riqueza familiar permite no polo rico do planeta gera uma pressão mundial por consumo e estilo de vida semelhante (FARFUS et al., 2007).

Questiona-se então, como as economias podem crescer reduzindo-se o consumo? Essa questão pode ser resolvida com a criação de novos mercados, por meio do desenvolvimento de negócios junto à base da pirâmide que, por ser composta por pessoas munidas de poucos recursos financeiros e serviços básicos, apresenta diversas oportunidades. Esse engajamento pode beneficiar a sociedade de uma forma global.

As organizações combinam tecnologias com insights vindos de gaps das comunidades locais. Nesse sentido, uma das possibilidades de atuação são alianças entre empresas. Grandes organizações possuem uma base de conhecimento global que não é facilmente acessível aos empreendedores locais que, por outro lado, 
possuem maleabilidade e disposição para atuação junto a mercados de menor poder aquisitivo. Em parceria eles podem criar negócios junto à base da pirâmide inovando socialmente. Para isso, podem ser feitas alianças com outras firmas locais ou com o próprio governo local (PRAHALAD; HART, 2002, RIBEIRO, 2013).

Outra possibilidade é a identificação das oportunidades de negócio que o mercado presente na base da pirâmide pode representar para aqueles que se dispõem a buscar novas capacidades para desenvolver negócios que atendam às necessidades dos mais pobres. Nesse sentido, desenvolver estratégias que busquem solucionar problemas sociais e ambientais, pode representar a possibilidade de alcançar esse mercado de quatro bilhões de pessoas que estão na base da pirâmide. Inovação e empreendedorismo têm efeitos positivos sobre a mudança social e econômica (SCHUMPETER, 1985) e é, portanto, um fator importante para o crescimento inclusivo.

De acordo com Maçaneiro e Cunha (2010), as políticas de inovação buscam o progresso da competitividade da economia do país e ainda colaboram com o crescimento econômico. As pequenas empresas têm um papel de elevada importância, pois são elas que geram o maior número de postos de trabalho e atendem a sociedade em muitas necessidades. Mas, torna-se fundamental que os negócios sejam desenvolvidos também com base em inovação social, na medida em que as organizações existem para satisfazerem, direta ou indiretamente, as necessidades e desejos das sociedades. De similar maneira, os empreendedores podem se inserir na base da pirâmide econômica criando negócios sociais por meio da inovação.

Pensar de forma inovadora sobre os processos decisórios que conduzem o planeta e o cotidiano das pessoas pode se traduzir em um posicionamento empreendedor que visa o bem estar econômico e social de todos, o que abre espaço para a descoberta de novas possibilidades e também para a obtenção de uma imagem positiva junto ao mercado. As dimensões sociais e ambientais da atividade empresarial deixam de ser consideradas externalidades que a sociedade deverá custear por meio de impostos e do setor público, para se tornar um fator intrínseco da atividade econômica. O fundamental é verificar que não é suficiente 
uma empresa desenvolver algumas atividades sociais para melhorar a imagem: é o próprio "core business", o negócio da empresa, que deve ser desenvolvido de forma responsável (FARFUS et al., 2007).

A emergência dos quatro bilhões de pessoas que integram a base da pirâmide representa uma oportunidade de mercado a ser explorada e também uma chance para os negócios, governo e sociedade civil de trabalharem juntos em uma causa comum. O desenvolvimento de negócios por meio de estratégias para a base da pirâmide dissolve conflitos entre defensores do comércio local e do capitalismo global por um lado, e fomenta a sustentabilidade social e ambiental por outro. Novos modelos de negócios que não provoquem disrupção das culturas locais e seus estilos de vida são importantes. Uma efetiva combinação do conhecimento local e global é demandada, em vez de uma imposição de velhos modelos a este mercado (HART, 2005; PRAHALAD; HART, 2002). Ou seja, o espaço para ideias empreendedoras se faz presente.

A avaliação da eficiência e eficácia de inovações sociais desenvolvidas por meio de estratégias de negócios cocriadas junto à base da pirâmide, não cabe ser mensurada ou demonstrada através de corte de custos, mas por atividades que criam valor (SMITH; SHARICZ, 2011). Nesse sentido, a inovação disruptiva, de que trata Christensen (1997), rompe e redefine a trajetória pela introdução de produtos que não apresentam tanta qualidade quanto os atualmente disponíveis, mas oferecem outros benefícios como simplicidade, conveniência e um custo menor, que clientes novos ou menos exigentes consideram relevantes. O entendimento sobre inovação disruptiva contribui para elucidar a relação implícita que existe entre trabalhar com a base da pirâmide e inovar socialmente. Ao desenvolver estratégias para servir à base da pirâmide, as firmas estarão inovando no mercado e com isso, obterão retornos atrelados ao pioneirismo (CHRISTENSEN; RAYNOR, 2003).

Ao atender o mercado existente na base da pirâmide, as empresas demonstram sua concepção integrada que associa o crescimento econômico ao aumento dos níveis de bem estar social. Assim, o desenvolvimento local busca rediscutir qualidade de vida, não pelo processo de acumulação, mas pela 
oportunidade de realização do indivíduo na integridade de sua existência (FARFUS et al., 2007).

As organizações, nesse sentido, podem alterar seu entendimento de escala de "maior é melhor" para operações em pequena escala, bem distribuídas, acopladas com capacidades em escala mundial. As tentativas de adotar o mesmo modelo de negócios do topo da pirâmide econômica na base demonstram estar fadadas ao insucesso. Adotar e impor à base da pirâmide a mesma forma de fazer negócios utilizada nos mercados ricos não se mostra propícia, pois este mercado possui peculiaridades, as quais são mais eficazmente atendidas por empreendedores e pequenas empresas ou com o auxílio deles (HART, 2005).

Algumas evidências empíricas fornecidas por Harjula (2006), Hawken, Lovins e Lovins (1999) e Van den Waeyenberg e Hens (2006), apontam que os mercados da base da pirâmide podem, portanto, oferecer oportunidades aos inovadores para estabelecer sua legitimidade (ROGERS, 2003). No estudo realizado por Hawken, Lovins e Lovins (1999) é possível observar o exemplo da rede de soluções da cidade de Curitiba no Brasil. A cidade desenvolveu soluções em rede ao reunir a iniciativa pública e privada, envolvendo a comunidade, como no exemplo do calçadão de pedestres, onde uma rua de intenso fluxo de veículos foi fechada e transformada em calçadão para uso exclusivo de pedestres, promovendo maior segurança e fluidez ao tráfego de pedestres, além de permitir um maior fluxo de clientes potencias nas lojas situadas no calçadão. Isto contribui para o desenvolvimento do comércio local e a prosperidade das pequenas empresas. $O$ caso demonstra que organizações de todo tipo, ao trabalharem com estratégias voltadas à base da pirâmide, podem inovar socialmente na medida em que acarreta melhoria de maneira sistêmica para todos.

Pequenas inovações podem promover novas oportunidades de criação ou crescimento de negócios, uma vez que o enfoque voltado para a base da pirâmide e para a inovação social abre espaço para uma visualização distinta de oportunidades. Além disso, o tamanho do mercado potencial permite vislumbrar um crescimento mais rápido. É importante a consciência da necessidade de se organizar a produção em entidades e processos sociais que aprimorem a qualidade de vida das pessoas 
individualmente e da comunidade como um todo (HAWKEN; LOVINS; LOVINS, 1999). Para isso, os empreendedores e pequenas empresas podem criar valor compartilhado de três maneiras distintas: por reconceber produtos e mercados; redefinindo a produtividade na cadeia de valor; e apoiando a construção de clusters de empreendimentos locais (KANIA; KRAMER, 2011).

O trabalho conjunto e compartilhado entre a sociedade e as empresas pode proporcionar o desenvolvimento de novos mercados e negócios, podendo ser concebidos por empreendedores e pequenas empresas, inclusive locais. A concepção, desenvolvimento e implementação de estratégias de negócios que contemplem questões de cunho social (entre outras) não é apenas uma demanda da realidade competitiva atual, mas também, uma forma de aperfeiçoar a organização para se manter em constante evolução no que diz respeito a capacidade de flexibilização e adaptação para atendimento aos diversos públicos consumidores, em especial, o que está localizado na base da pirâmide com todas as suas peculiaridades (NOBRE; RIBEIRO, 2013).

\section{Considerações Finais}

O casamento entre o desenvolvimento e adoção de estratégias de negócios voltados para a base da pirâmide e a geração de inovações sociais pode se traduzir em uma gestão sustentável, que se apresenta na capacidade da empresa em analisar o ambiente e conhecer melhor o mercado, perseguindo alternativas de melhoria contínua de produtos e processos que permitam gerar valor. Sendo um desafio permanente de avanço, progresso e modernidade (FARFUS et al., 2007).

A criação de valor compartilhado se estende além de simples práticas. Ele é criado quando os empreendedores e empresas geram valor econômico para si de uma forma que simultaneamente produz valor para a sociedade, abordando desafios sociais e ambientais (KANIA; KRAMER, 2011). O desenvolvimento de novos modelos de negócios para o atendimento dos anseios da base da pirâmide, sendo realizado de uma maneira socialmente sustentável, demonstra que a empresa 
investe no desenvolvimento de inovações sociais para contribuir com a transformação da sociedade de uma maneira equilibrada e justa.

Os empreendedores e as pequenas empresas têm uma inexplorada oportunidade de mercado na base da pirâmide em decorrência das novas exigências que a sociedade impõe às organizações, que devem contribuir para o desenvolvimento sustentável. Os empreendedores e as pequenas empresas podem ajudar as grandes corporações, por encontrarem-se mais próximas à população mais pobre e terem maior capacidade de desenvolver projetos em conjunto com as comunidades locais por meio de parcerias onde possam, por exemplo, extrair matéria-prima por meio de manejo sustentável, utilizando a mão de obra da própria comunidade, gerando renda e possibilitando a autossuficiência econômica dessas comunidades (FERRO, 2006).

Hart (2005) apresenta dados que apontam que os pobres sempre pagam de duas a vinte vezes mais do que os consumidores do topo da pirâmide por bens e serviços básicos como água, alimentos, remédios, dentre outros. Grandes empresas buscam aumentar a produtividade do trabalho, empregando menos e produzindo mais. As pequenas empresas contribuem na medida em que são os maiores empregadores, pois representam a maior fatia das empresas. Os empreendedores e pequenas empresas, ao olharem para a base da pirâmide, podem identificar negócios sociais, contribuir para a transformação da sociedade de maneira positiva e encontrar, ao mesmo tempo, novas oportunidades de negócio em um mercado pouco explorado.

As organizações, as escolas de negócios e os próprios profissionais já atuantes, podem aproveitar as oportunidades de desenvolver negócios e aperfeiçoar os existentes e ainda, contribuir para um mundo melhor a partir da resolução de problemas atrelados à pobreza e fosso social entre os mais ricos e os mais pobres. O Estado deve ser ativo na adoção e no fomento de tais iniciativas que visem à resolução de problemas sociais, possibilitando o encontro das organizações com conhecimento global e a comunidade com sua expertise local. Quando são desenvolvidos ou criados novos modelos de negócios que inter-relacionam a necessidade de atendimento da base da pirâmide e a criação de inovação social, 
contribui-se para a melhoria da comunidade local e da sociedade global, podendo-se identificar ao mesmo tempo relevantes mercados a serem explorados.

Esta pesquisa inicia uma discussão sobre as oportunidades abertas a empreendedores e pequenas empresas ao explorar a base da pirâmide. Pequenos empreendimentos podem ser criados por meio da inovação social, baseados em uma visão holística e agregando valor ao negócio. Isto pode gerar uma vantagem competitiva que, muitas vezes, só podem ser alcançadas por quem estiver próximo ao público-alvo.

Por fim, vale dizer que outras pesquisas ainda podem explorar, empiricamente, os empreendedores que estão atentos às oportunidades contra aqueles que já possuem seu negócio e estão conscientes de todas as implicações de seus empreendimentos, bem como estas diferenças moldam resultados produtivos.

\section{Referências:}

BEHRMAN, J.; GAVIRIA, A.; SZEKELY, M. Who's In and Who's Out: Social Exclusion in Latin America. Washington, DC: Inter-American Development Bank, 2003.

BRUNSTEIN, J; RODRIGUES, A. L; KIRSCHBAUM, C. Inovação social e empreendedorismo institucional: a ação da ONG "ação educativa" no campo educacional da cidade de São Paulo. Organizações \& Sociedade, v. 15, n. 46, p. 119-136, 2008.

CAMPANHOLO, T.; FONTES, G. G. D. O.; ALVES, A. A riqueza na base da pirâmide - inclusão social pelo consumo e criação de novos mercados. Revista da Católica, Uberlândia, v. 2, n. 3, p. 6-20, 2010.

CÂNDIDO, A. C. Inovação Disruptiva: Reflexões sobre as suas características e implicações no mercado. Campus da Caparica: Universidade Nova de Lisboa, IET Research Center on Enterprise and Work Innovation. (2012). Disponível em: <http://run.unl.pt/bitstream/10362/6912/1/WPSeries_05_2011ACC\%C3\%A2ndido 1.pdf>. Acesso em: 12 dez. 2012.

CHRISTENSEN, C. M. The innovator's dilemma: when new technologies cause great firms to fail. Boston: Harvard Business School Press, 1997. 
CHRISTENSEN, C. M.; RAYNOR, M. E. The innovator's solution. O crescimento pela inovação: como crescer de forma sustentada e reinventar o sucesso. SERRA, Afonso Celso da Cunha (Trad.). Rio de Janeiro: Elsevier, 2003.

DAGNINO, R. P (Org.). Tecnologia social: ferramenta para construir outra sociedade. Campinas, SP: IG/UNICAMP, 2009.

DAGNINO, R. P.; BRANDÃO, F. C.; NOVAES, H. T. Sobre o marco analítico conceitual da tecnologia social. In: LASSANCE Jr. et al. Tecnologia Social uma estratégia para o desenvolvimento. Rio de Janeiro: Fundação Banco do Brasil, 2004, p.15-64.

DAGNINO, R. P.; GOMES, E. Sistema de inovação social para prefeituras. In: CONFERÊNCIA NACIONAL DE CIÊNCIA E TECNOLOGIA PARA INOVAÇÃO. Anais... São Paulo, 2000.

DOSI, G. Technological paradigms and technological trajectories. Research Policy, v. 11, 1982.

FARFUS, D. et al. Inovações sociais. Curitiba: SESI/SENAI/IEL/UNINDUS, 2007.

FERRO, A. F. P. et al. Oportunidades tecnológicas e estratégias concorrenciais de gestão ambiental: o uso sustentável da biodiversidade brasileira. Revista Gestão e Produção, v. 13, n. 3, p. 489-501, 2006.

FLEURY, S. Observatório da inovação social. In: Congresso Internacional del Clad sobre la Reforma Del Estado Y de la Administración Pública, 9 (2001). Buenos Aires. Anais Congresso Internacional del Clad sobre la Reforma Del Estado Y de la Administración Pública, Buenos Aires, 2001.

GORDON, M.; DAKSHINAMOORTHY, V.; WANG, L., The Benefits, Innovations, and Uses of Information and Communication Technology at the Base of the Pyramid. In: INTERNATIONAL CONFERENCE ON INFORMATION SYSTEMS (ICIS 2006), Milwaukee, USA, 2006. Proceedings ICIS 2006. Milwaukee, USA, 2006, Paper 103. Disponível em: <http://aisel.aisnet.org/icis2006/103>. Acesso em: 12 mar. 2013.

HAMMOND, A. A.; PRAHALAD, C.K. Selling to the Poor. Foreign Policy, 2004.

HARJULA, L. Tensions between venture capitalists and business-social entrepreneurs goals. Greener Management International, v. 51, p. 79-87, 2006.

HART, S. L. A. Natural-Resource-Based View of the Firm. The Academy of Management Review, v. 20, n. 4, p. 986-1014, 1995. Disponível em: $<$ http://www.cbe.wwu.edu/dunn/ rprnts.naturalresourceviewofthefirm.pdf $>$. Acesso em: 13 mai. 2011.

RIBEIRO, R. E. M; SEGATTO, A. P; COELHO, T. R. Inovação social e estratégia para a base da pirâmide: mercado potencial para empreendedores e pequenos negócios. Revista de Empreendedorismo e Gestão de Pequenas Empresas, v. 2, n.2, p.55-72, 2013. 
. Capitalism at the Crossroads: The Unlimited Business Opportunities in Solving the World's Most Difficult Problems. Upper Saddle River, NJ: Wharton School Publishing, 2005.

HART, S. L.; CHRISTENSEN, C. M. The Great Leap: Driving Innovation from the Base of the Pyramid. MIT Sloan Management Review, october 15 (2002).

Disponível em:

<http://www.stuartlhart.com/sites/stuartlhart.com/files/Hart\%20\%20Christensen \%20Sloan\%202003_0.pdf>. Acesso em: 20 out. 2012.

HART, S. L.; DOWELL, G. A Natural-Resource-Based View of the Firm: Fifteen Years After. Journal of Management, December 2010.

doi:10.1177/0149206310390219

HART, S.L.; MILSTEIN, M. B. Creating sustainable value. Academy of Management Executive, v. 17, n. 2, p. 56-67, 2003.

HAWKEN, P.; LOVINS, A.; LOVINS, L. H. Capitalismo natural: criando a próxima revolução industrial. São Paulo: Cultrix, 1999.

KANIA, J.; KRAMER, M. Q\&A Roundtable on Shared Value. Moderated by John Kania \& Mark Kramer. Stanford Social Innovation Review, Summer, 2011.

LINHARES, M. V. D. C.H.O.Q.U.E. - Tratamento para o Surto Empreendedor. 1. ed. Teresina: 2013. 152 p. Disponível em:

<http://www.institutomulticom.com/choque/livro/choque.pdf>. Acesso: 23 mai. 2013.

MAÇANEIRO, M. B.; CUNHA, S. K. Eco-Inovação: um quadro de referência para pesquisas futuras. Simpósio, 2010.

MATTEN, D.; CRANE, A. Corporate citizenship: toward an extended theoretical conceptualization. Academy of Management Review, v. 30, p. 166-179, 2005.

NOBRE, F. S.; RIBEIRO, R. E. M. Cognição e Sustentabilidade: Estudo de Casos Múltiplos no Índice de Sustentabilidade Empresarial da BM\&FBovespa. Revista de Administração Contemporânea, v.17, n.4. p. 499-517, Jul./Ago. 2013.

OECD. The Oslo Manual: The Measurement of Scientific and Technical Activities. Paris: OECD; Eurostat, 1997.

PEREDO, A. M.; MCLEAN, M. Social entrepreneurship: a critical review of the concept. Journal of World Business, v. 41, n. 1, p. 56-65, 2006.

PRAHALAD, C. K.; HART, S. L. The Fortune at the Bottom of the Pyramid. Strategy + Business, v. 26, 2002.

RIBEIRO, R. E. M; SEGATTO, A. P; COELHO, T. R. Inovação social e estratégia para a base da pirâmide: mercado potencial para empreendedores e pequenos negócios. Revista de Empreendedorismo e Gestão de Pequenas Empresas, v. 2, n.2, p.55-72, 2013. 
PRAHALAD, C.K. The Fortune at the Bottom of the Pyramid: eradicating poverty trough profits. USA: Prentice Hall, 2006.

RIBEIRO, R. E. M. Cognição e sustentabilidade: estudo de casos múltiplos no índice de sustentabilidade empresarial (ise) da BM\&F Bovespa. Curitiba, 2013. 214p. Dissertação (Mestrado em Administração) Programa de Pós-graduação em Administração, Universidade Federal do Paraná, 2013.

ROGERS, E. Diffusion of Innovations. 5 ed. New York: Free Press, 2003.

SARKAR, S. O empreendedor inovador: faça diferente e conquiste seu espaço no mercado. Rio de Janeiro: Elsevier, 2008.

SMITH, P. A. C.; SHARICZ, C. The shift needed for sustainability. The Learning Organization, v. 18, n. 1, 2011. p. 73-86. doi 10.1108/09696471111096019.

SCHUMPETER, J. A Teoria do Desenvolvimento Econômico. São Paulo: Nova Cultural, 1985.

. Economic Theory and Entrepreneurial History. Revista Brasileira de Inovação, v. 1, n. 2, jul., 2002, Rio de Janeiro, R.J.; FINEP, 2002.

UNESCO. Década da educação das nações unidas para um desenvolvimento sustentável, 2005-2014: documento final do esquema internacional de implementação. - Brasília: UNESCO, 2005.

VAN DEN WAEYENBERG, S.; HENS, L. Crossing the bridge to poverty, with lowcost cars. Journal of Consumer Marketing, v. 25, p. 439-445, 2006.

Artigo recebido em 13/11/2012. Aprovado em: 03/04/2013. 